\title{
Development of Cognitive Skills and Critical Thinking through Participation in the International Citizen Science project "Tree bodyguards"
}

\author{
Danguole Saviciene \\ Visaginas city "Verdenes" gymnasium, Lithuania
}

\begin{abstract}
The report presents good work experience organizing nature studies learning activities for primary school students. The report tells how lithuanian students from Visaginas „Verdenès“ Gymnasium joined the international citizen science project "Tree bodyguards" and carried out an experiment using the methodology "Evaluation of predation using artificial caterpillars and leaf samples". The citizen science project is an increasingly popular practice in the world, when data can be collected by anyone who wants and later on can be valued by scientists and used in real scientific research.

The report describes the preparation for the experiment „Evaluation of predation by artificial caterpillars and leaf samples“, its performance (raising the hypothesis with students, observation of the object, collecting the data and making the conclusions) and reflection creating the methodological tool - educational video film (internet access https://www.youtube.com/watch?v=Q067hOcUDK4), presenting it to others.

The report discloses attractive learning methods that interest students in the subject, enable them to act on their own - to perform practical activity, to share work success with others, to feel civic in response to the invitation from French researchers Bastien Castagneyrol and Elena Valdes Correcher from the University of Bordeaux to participate in the project.
\end{abstract}

Keywords: stages of experiment, learning methods, educational video film creation, nature studies lesson, elementary school students, citizen science project. 